\title{
Adipose tissue-derived stromal/stem cells + cholecalciferol: a pilot study in recent-onset type 1 diabetes patients
}

${ }^{1}$ Departamento de Nutrologia e Diabetes, Universidade Federal do Rio de Janeiro, RJ, Brasil ${ }^{2}$ Laboratório de Bioengenharia de Tecidos, Instituto Nacional de Metrologia, Qualidade e Tecnologia (Inmetro), Universidade Federal do Rio de Janeiro, Rio de Janeiro, RJ, Brasil

${ }^{3}$ Serviço de Patologia Clínica, Universidade Federal do Rio de Janeiro, Rio de Janeiro, RJ, Brasil ${ }^{4}$ Instituto de Estudos de Saúde Pública, Universidade Federal do Rio de Janeiro, Rio de Janeiro, RJ, Brasil

${ }^{5}$ Faculdade de Medicina, Universidade Federal do Rio de Janeiro, Rio de Janeiro, RJ, Brasil

${ }^{6}$ Departamento de Cirurgia Plástica, Universidade Federal do Rio de Janeiro, Rio de Janeiro, RJ, Brasil ${ }^{7}$ Universidade Federal de São Paulo, São Paulo, SP, Brasil ${ }^{8}$ Universidade de São Paulo, São Paulo, SP, Brasil

${ }^{9}$ Departamento de Hematologia, Universidade Federal do Rio de Janeiro, Rio de Janeiro, RJ, Brasil ${ }^{10}$ Core Cell Technology, Pontifícia Universidade Católica do Paraná, Curitiba, PR, Brasil

${ }^{11}$ Centro Multidisciplinar de Pesquisas Biológicas (Numpex-Bio), Universidade Federal do Rio de Janeiro, Rio de Janeiro, RJ, Brasil; Laboratório de Bioengenharia de Tecidos, Instituto Nacional de Metrologia, Qualidade e Tecnologia (Inmetro), Rio de Janeiro, RJ, Brasil

\author{
Joana Rodrigues Dantas ${ }^{1}$ \\ https://orcid.org/0000-0002-6088-2813 \\ Débora Batista Araújo' \\ https://orcid.org/0000-0003-2969-9559 \\ Karina Ribeiro Silva ${ }^{2}$ \\ https://orcid.org/0000-0001-7394-2494 \\ Débora Lopes Souto ${ }^{1}$ \\ https://orcid.org/0000-0002-5149-0391 \\ Maria de Fátima Carvalho Pereira ${ }^{3}$ \\ https://orcid.org/0000-0003-3932-6481 \\ Ronir Raggio Luiz ${ }^{4}$ \\ https://orcid.org/0000-0002-7784-9905 \\ Matheus dos Santos Mantuano \\ https://orcid.org/0000-0002-2118-4879 \\ Cesar Claudio-da-Silva 6 \\ https://orcid.org/0000-0002-3786-3702 \\ Monica Andrade Lima Gabbay ${ }^{7}$ \\ https://orcid.org/0000-0002-1300-9675 \\ Sérgio Atala Dib ${ }^{8}$ \\ https://orcid.org/0000-0001-8653-8773 \\ Carlos Eduardo Barra Couri ${ }^{9}$ \\ https://orcid.org/0000-0002-0951-9824 \\ Angelo Maiolino 9 \\ https://orcid.org/0000-0003-0140-9548 \\ Carmen Lúcia Kuniyoshi Rebelatto ${ }^{10}$ \\ https://orcid.org/0000-0003-1407-0416 \\ Débora Regina Daga ${ }^{10}$ \\ https://orcid.org/0000-0003-2241-4442 \\ Alexandra Cristina Senegaglia ${ }^{10}$ \\ https://orcid.org/0000-0002-8052-6357 \\ Paulo Roberto Slud Brofman ${ }^{10}$ \\ https://orcid.org/0000-0001-6401-782X \\ Leandra S. Baptista ${ }^{11}$ \\ https://orcid.org/0000-0001-9998-8044 \\ José Egídio Paulo de Oliveira ${ }^{1}$ \\ https://orcid.org/0000-0002-4422-9806 \\ Lenita Zajdenverg ${ }^{1}$ \\ https://orcid.org/0000-0002-1579-3299 \\ Melanie Rodacki \\ https://orcid.org/0000-0002-9007-1325
}

\author{
Correspondence to: \\ Débora Lopes Souto \\ Rua Professor Rodolfo Paulo Roco, \\ 255, $9^{\circ}$ andar, sala 09 E 14 , Ilha do \\ Fundão - 21941-913 - Rio de Janeiro, \\ RJ, Brasil \\ deboralopessouto@gmail.com \\ Received on Dec/10/2020 \\ Accepted on Feb/3/2021
}

DOI: 10.20945/2359-3997000000368

\section{ABSTRACT}

Objective: Adipose tissue-derived stromal/stem cells (ASCs) and vitamin D have immunomodulatory actions that could be useful for type 1 diabetes (T1D). We aimed in this study to investigate the safety and efficacy of ASCs + daily cholecalciferol (VIT D) for 6 months in patients with recent-onset T1D. Materials and methods: In this prospective, dual-center, open trial, patients with recent onset T1D received one dose of allogenic ASC $\left(1 \times 10^{6} \mathrm{cells} / \mathrm{kg}\right)$ and cholecalciferol 2,000 Ul/day for 6 months (group 1). They were compared to patients who received chol-ecalciferol (group 2) and standard treatment (group 3). Adverse events were recorded; C-peptide (CP), insulin dose and HbA1c were measured at baseline (TO), after 3 (T3) and 6 months (T6). Results: In group 1 ( $n=7)$, adverse events included transient headache (all), mild local reactions (all), tachycardia $(n=4)$, abdominal cramps ( $n=$ 1), thrombophlebitis $(n=4)$, scotomas $(n=2)$, and central retinal vein occlusion atT3 $(n=1$, resolution at T6). Group 1 had an increase in basal CP ( $p=0.018$; mean: 40.41+/-40.79\%), without changes in stimulated CP after mixed meal $(p=0.62)$, from T0 toT6. Basal CP remained stable in groups 2 and 3 ( $p$ $=0.58$ and $p=0.116$, respectively). Group 1 had small insulin requirements $(0.31+/-0.26 \mathrm{UI} / \mathrm{kg}) \mathrm{without}$ changes atT6 $(p=0.44)$ and $\mathrm{HbA} 1 \mathrm{c}$ decline $(p=0.01)$. AtT6, all patients $(100 \% ; n=7)$ in group 1 were in honeymoon vs $75 \%(n=3 / 4)$ and $50 \%(n=3 / 6)$ in groups 2 and $3, p=0.01$. Conclusions: Allogenic ASC + VIT D without immunosuppression was safe and might have a role in the preservation of $\beta$-cells in patients with recent-onset T1D. ClinicalTrials.gov: NCT03920397. Arch Endocrinol Metab. 2021;65(3):342-51

Keywords

Type 1 diabetes; pancreatic function; adipose tissue-derived stromal/stem cells 


\section{INTRODUCTION}

$\mathrm{T}$ ype 1 diabetes (TID) is a chronic disease characterized by immune-mediated destruction of pancreatic $\beta$-cells requiring life-long insulin treatment. Preservation or recovery of residual $\beta$-cells could cure the disease (1-4) and avoid insulin requirements. Even a partial response, unable to induce cure, appears to be beneficial, leading to lower insulin doses and reduced frequency of both severe hypoglycemia and chronic complications (5).

Immunomodulatory and immunosuppressive agents have been tested to preserve $\beta$-cell function (6-8). Non-myeloablative transplantation of autologous hematopoietic stem cells (HSC) showed favorable results and exogenous insulin withdrawal (at least for a short period) in individuals with TID, but it requires immunosuppression (9). Mesenchymal stem cells (MSCs) are potential alternatives due to their immunomodulatory properties without the need for immunosuppression $(10,11)$. MSCs decrease proliferation and activation of natural killers (NK), dendritic and $\mathrm{T}$ cells, reduce secretion of inflammatory cytokines and may have antiapoptotic properties (12). Therefore, they may have a protective role in the autoimmune destruction of $\beta$-cells. Adipose tissue represents an abundant and easily accessible source of MSCs (13), which may be of great clinical interest.

Vitamin D is another potential immunomodulatory agent. In vitro and in vivo studies suggest that $25(\mathrm{OH})$ vitamin $\mathrm{D}$ inhibits lymphocyte proliferation and modifies the Thl/Th2 cytokine profile, which may reduce damage associated with the Thl immune response $(14,15)$. Gabbay and cols. have shown preservation of C-peptide (CP) secretion with 2,000 UI/day of vitamin D (VIT D) (16) in patients with recent-onset TID. However, the benefits of VIT D supplementation are still controversial (17-19).

T1D has a complex pathophysiology that involves multiple immune pathways. Thus, it is probable that the ideal intervention for its cure would include a combination of drugs with different mechanisms of actions. The aim of this study was to investigate the safety and efficacy of adipose tissue-derived stromal/ stem cells (ASCs) infusion + daily cholecalciferol (VIT D) for 6 months in patients with recent-onset TlD. We also performed a pilot analysis comparing these results with those obtained from a previous case control study that investigated the effect of solely VIT D supplementation in patients with TID (16).

\section{RESEARCH DESIGN AND METHODS}

\section{Patient selection and study design}

This was a prospective, dual-center, open trial in which patients with recent onset TID received one dose of allogenic ASC and VIT D 2,000 UI/day for 6 months. The sample was selected by convenience. Participants signed an informed consent. The study was approved by the Institutional Review Board (17488313.1.0000.5257, University Hospital Clementino Fraga Filho [HUCFF]) and registered at ClinicalTrial.gov (NCT03920397). Inclusion criteria were diagnosis of TID according to American Diabetes Association (ADA) criteria for $<4$ months; ages between 16 and 35 years, and positive glutamic acid decarboxylase antibody (GADA). Malignancy, infections, pregnancy, breastfeeding, renal dysfunction and diabetic ketoacidosis were exclusion criteria.

\section{Lipoaspirate human samples and ASC culture}

Adipose tissue samples were obtained through liposuction of three healthy females. Donor's serology testing was negative for syphilis, Chagas disease, Hepatitis B and C, HIV and HTLV. Donors had Cytomegalovirus IgG+ with negative polymerase chain reaction (PCR) in blood samples and ASCs.

ASCs were isolated, cultured and characterized as previously described (13). Samples were processed at the Core Cell Technology facility of Pontifícia Universidade Católica do Paraná. Briefly, $100 \mathrm{~mL}$ of adipose tissue was washed in sterile phosphate-buffered saline (PBS) (Gibco Invitrogen). A one-step digestion by $\mathrm{l} \mathrm{mg} / \mathrm{mL}$ collagenase type I (Invitrogen) was performed for 30 minutes at $37{ }^{\circ} \mathrm{C}$ during permanent shaking, followed by a filtration step through a $100 \mu \mathrm{m}$ mesh filter (BD FALCON, BD Biosciences Discovery Labware). The cell suspension was centrifuged at $800 \mathrm{~g}$ for 10 minutes, and erythrocytes were removed through a lysis buffer with $\mathrm{pH}$ 7.3. The remaining cells were washed at $400 \mathrm{~g}$ for 10 minutes and then cultured at a density of $1 \times 10^{5}$ cells $/ \mathrm{cm}^{2}$ in T75 culture flasks and DMEM-Fl2 (Gibco Invitrogen) supplemented with $10 \%$ of fetal calf serum, penicillin (100 units $/ \mathrm{mL})$, and streptomycin $(100 \mu \mathrm{g} / \mathrm{mL})$. The culture medium was replaced three days after seeding, and then twice a week. ASCs were subcultured after reaching $80 \%$ confluence, with $0.5 \%$ trypsin/EDTA (Invitrogen) solution. Cells were related at a density of $4 \times 10^{3}$ cells $/ \mathrm{cm}^{2}$ for expansion (13). 
Quality control of cell suspension sterility was evaluated by tests to detect bacteria and fungi (Bact/ Alert 3D, Biomerieux), endotoxins (Endosafe ${ }^{\mathrm{TM}}$ PTS, Charles River) and Mycoplasma (KIT MycoAlert ${ }^{\mathrm{TM}}$ PLUS Mycoplasma Detection, Lonza). Cell viability was performed by flow cytometry using the vital dye 7-AAD (7-Aminoactinomycin D - BD\#559925) to determine the percentage of viable cells and Annexin V protein (BD\#51-65875X) to determine the percentage of cells in apoptosis. Cytogenetic analysis was performed using the GTG-banding method.

Cells were phenotypically characterized by flow cytometry before the clinical application, using the following monoclonal antibodies: FITC-labeled CD14 (BD\#555397), CD45 (BD\#555482), CD19 (BD\#555412), CD44 (BD\#555478); PE-labeled CD73 (BD\#550257), CD90 (BD\#555596), CDl66 (BD\#559263), PerCP-labeled HLA-DR (BD\#551375); APC-labeled CD34 (BD\#555824), CD105 (BD\#562408), CD29 (BD\#559883) all purchased from BD (Pharmingen). At least 100,000 events were acquired on a BD FACSCalibur ${ }^{\mathrm{TM}}$ flow cytometer (BD Biosciences), and data were analyzed using FlowJo 10 (TreeStar) software (13) (Supplementary Material - Supplementary Table S1).

\section{ASC infusion}

On the day of infusion, the ASC monolayer were dissociated as described above, and $1 \times 10^{6}$ cells $/ \mathrm{kg}$ of the recipient patient were resuspended in $5 \mathrm{~mL}$ of saline solution with 50\% albumin and 5\% ACD (Anticoagulant Citrate Dextrose Solution). The Cell suspension was sent to the hospital in a cooler with recycled ice.

Patients that received ASCs were admitted to the hospital on the day of the infusion and discharged 24 hours after infusion. A single dose of ASCs was infused in a peripheral upper arm vein for 15-20 minutes. Patients started taking oral cholecalciferol 2,000 UI one day after the infusion of ASCs.

\section{Safety tests}

Adverse events were recorded during hospitalization and at each follow-up outpatient visit (T1, T3, and T6), with clinical and laboratory exams (blood count, lipids, renal and hepatic function, TSH, free tyroxine, anti-TPO, calcium, phosphorus and $25(\mathrm{OH})$ vitamin $\mathrm{D}$, performed with automated biochemical equipment CMD 800 IXI).

\section{Clinical and pancreatic function evaluation}

Participants were followed for 6 months. In the first visit (T0), all patients were interviewed and had a physical exam. Weight, height, body mass index (BMI), blood pressure, heart frequency, frequency of hypoglycemia and insulin dose $/ \mathrm{kg}$ of body weight were evaluated at $\mathrm{T} 0$ and after 1 (Tl), 3 (T3) and 6 (T6) months. Insulin dose adjustments were performed at each visit as necessary. Patients received nutritional guidance according to ADA recommendations (20). Blood samples were drawn at $\mathrm{T} 0, \mathrm{~T} 1, \mathrm{~T} 3$ and $\mathrm{T} 6$ for the following measurements: HbAlc (High Performance Liquid Chromatography by boronate affinity), blood count and biochemistry analysis, $25(\mathrm{OH})$ vitamin $\mathrm{D}$ (automated CMD 800 IXI), GADA (ELISA assay, Euroimmun brand and Molecular Devices Spectra max reader) and CP (Microparticle Chemiluminescent Immunoassay, Architect Abbott) before and 30, 60, 90 and 120 minutes after liquid mixed meal (Glucerna $\left.{ }^{\circledR}\right)$. The area under the curve (AUC) for CP was calculated. Adverse events were recorded during hospitalization and at each follow-up visit.

\section{Comparison with previous case-control study using only VIT D supplementation as intervention}

We compared our results with patients previously included in a case-control study that investigated the effects of a daily dose of 2,000 UI VIT D without ASC in individuals with recent onset TID and similar age (>15 y/o), from a different population (São Paulo) in the same region of the country, Southeastern Brazil (16). Therefore, we established three patient groups for comparison: 1) ASCs + VIT D supplementation; 2) VIT D supplementation; 3) Conventional treatment. Group 3 comprised individuals from both centers: Rio de Janeiro $(\mathrm{n}=2)$ and São Paulo $(\mathrm{n}=4)$. Insulin therapy was prescribed for all patients. Dose adjustments were performed according to glycemic control. Changes in $\mathrm{HbAlc}, \mathrm{CP}$ and insulin dose/ $\mathrm{kg}$ were compared between groups. CP was analyzed by immunofluorometric assay (AutoDelfia) at T0 and T6, considering basal and peak stimulated CP after a mixed-meal test (MMT). AUC was not available for comparison.

\section{Statistical analysis}

Data are expressed as mean \pm standard deviation. Descriptive statistics have been used to summarize patients' characteristics. Comparisons of categorical 
variables were performed with Chi square test. A Wilcoxon test was used to compare results at baseline and after follow-up in each group. Continuous variables were compared using Kruskal-Wallis for multiplegroup comparison and Mann-Whitney for two-by-two comparisons. A Spearman test was used to investigate correlation between continuous variables. Statistical tests are based on a 2-sided significance level of 0.05 . For multiple comparisons, Bonferroni correction was applied and the significance level of 0.017 was considered. SPSS software, version 21.0 was used for statistical analyses.

\section{RESULTS}

\section{Clinical characteristics of the study group}

Eleven patients were interviewed, and two were excluded (one used glucocorticoid, and another had renal dysfunction). Nine patients were evaluated: seven received ASCs + VIT D and two were included as controls. All completed 6 months of follow-ups.

The mean age of patients that underwent intervention was $27.14 \pm 6.49$ years old; 3 were males, and 2 were non-whites. The TID duration at T0 was $2.6 \pm 1.03$ months. Mean initial serum $25(\mathrm{OH})$ vitamin $\mathrm{D}$ was $33.06 \pm 13.55 \mathrm{ng} / \mathrm{mL}$, patients were not taking any vitamin supplementation prior to the study. The control patients were 16 and 20 years old. Clinical characteristics of the study group are described in Table 1 .

\section{ASC infusion and adverse events}

For ASC infusion, the mean number of cells was $67.71 \times 10^{6}$, with $95.10 \%$ cell viability. Tests for a microorganism's growth control were negative. ASCs were immunophenotypically characterized as follows: CD105: 94.18\%; CD73: 96.46\%; CD90: 99.80\%; CD29: 99.15\%; CDl66: 94.04\%; CD44: 89.13\%; CD14:1.94\%; CD34: 0.59\%; CD45: 0.87\%; CD19: 0.71\%; HLA-DR: $0.64 \%$. No clonal chromosomal rearrangements were detected. Samples were approved by cytogenetic quality control for therapeutic use.

All patients had transient headache and mild local infusion reactions. Other immediate adverse events were tachycardia $(\mathrm{n}=4)$ and abdominal cramps $(\mathrm{n}=1)$. Four patients developed local thrombophlebitis within the first week and two had transient mild eye floaters during infusion, with no subsequent visual abnormalities. One patient developed central retinal vein occlusion at T3, with complete resolution at T6.

\section{Insulin dose, glycemic control and GADA status in ASC + VIT D group}

In those who received ASC + VIT D, the mean insulin dose at baseline was $0.31 \pm 0.26 \mathrm{UI} / \mathrm{kg}$. Insulin dose $/ \mathrm{kg}$ remained stable at T6 compared to T0 $(\mathrm{p}=0.44)$, except for one patient who became insulin free for 4 months. Insulin doses $/ \mathrm{kg}$ at $\mathrm{Tl}, \mathrm{T} 3$ and T6 were $0.26 \pm 0.21 \mathrm{UI} / \mathrm{kg}, 0.25 \pm 0.17 \mathrm{UI} / \mathrm{kg}$ and $0.28 \pm 0.14 \mathrm{UI} / \mathrm{kg}$, respectively. After intervention, there was a decrease in $\mathrm{HbAlc}(7.77 \pm 1.14 \%$ at $\mathrm{T} 0$, $6.21 \pm 0.49 \%$ at $\mathrm{T} 3$ and $6.56 \pm 0.66 \%$ at $\mathrm{T} 6$; T0 vs T6 $\mathrm{p}=0.018)$. Mean GADA titers remained stable throughout the study $(227.65 \pm 107.94$ units $/ \mathrm{mL}$ at $\mathrm{T} 0$ and $228.51 \pm 125.96$ units $/ \mathrm{mL}$ at $\mathrm{T} 6 ; \mathrm{p}=0.91$ ).

Table 1. Clinical Characteristics of each patient in the ASC + VIT D group

\begin{tabular}{|c|c|c|c|c|c|c|}
\hline & Age & Gender & Ethnicity & Body mass index & Disease duration & ASC concentration \\
\hline Patient 1 & 26 & Male & White & $26.06 \mathrm{~kg} / \mathrm{m}^{2}$ & 4 months & $78 \times 10^{6}$ cells \\
\hline Patient 2 & 35 & Male & Non-white & $25.91 \mathrm{~kg} / \mathrm{m}^{2}$ & 4 months & $74 \times 10^{6}$ cells \\
\hline Patient 3 & 28 & Male & White & $23.38 \mathrm{~kg} / \mathrm{m}^{2}$ & 2 months & $65 \times 10^{6}$ cells \\
\hline Patient 4 & 34 & Female & White & $23.56 \mathrm{~kg} / \mathrm{m}^{2}$ & 2 months & $73 \times 10^{6}$ cells \\
\hline Patient 5 & 16 & Female & White & $20.96 \mathrm{~kg} / \mathrm{m}^{2}$ & 3.5 months & $55 \times 10^{6}$ cells \\
\hline Patient 6 & 23 & Female & Non-white & $20.76 \mathrm{~kg} / \mathrm{m}^{2}$ & 1.7 months & $60 \times 10^{6}$ cells \\
\hline Patient 7 & 28 & Female & White & $23.71 \mathrm{~kg} / \mathrm{m}^{2}$ & 2 months & $69 \times 10^{6}$ cells \\
\hline Patient 8 & 16 & Male & White & $18.25 \mathrm{~kg} / \mathrm{m}^{2}$ & 2 months & Control \\
\hline Patient 9 & 20 & Female & Non-white & $23,71 \mathrm{~kg} / \mathrm{m}^{2}$ & 4 months & Control \\
\hline
\end{tabular}

kg: kilograms; m: meters; ASC: adipose tissue-derived stem/stromal cells. 


\section{Evaluation of pancreatic function in ASC + VITD group}

All patients who received ASC + VITD had an increase in basal CP 6 months after intervention $(\mathrm{T} 0=0.80 \pm$ $0.38 \mathrm{ng} / \mathrm{dL} ; \mathrm{Tl}=0.86 \pm 0.48 \mathrm{ng} / \mathrm{dL} ; \mathrm{T} 3=0.74 \pm$ $0.28 \mathrm{ng} / \mathrm{dL} ; \mathrm{T} 6: 1.04 \pm 0.47 \mathrm{ng} / \mathrm{dL}$; T0 vs. T6 p = 0.018 ), as shown in Figure 1. The mean increase was $40.41 \pm 40.79 \%$.

Both peak $\mathrm{CP}$ and AUC after MMT remained stable 6 months after ASC + VIT D ( $\mathrm{p}=1.0$ and $\mathrm{p}$ $=0.62)$. Peak $\mathrm{CP}$ before intervention, at $\mathrm{T} 3$ and at T6 were $2.83 \pm 1.24 \mathrm{ng} / \mathrm{dL}, 2.65+/-1.46 \mathrm{ng} / \mathrm{dL}$ and $2.82 \pm 1.24 \mathrm{ng} / \mathrm{dL}$, respectively (Figure 2 ). AUC before intervention and at $\mathrm{T} 1, \mathrm{~T} 3$ and $\mathrm{T} 6$ were 237.08 $\pm 95.18 \mathrm{ng} / \mathrm{mL}, 256.82 \pm 138.4 \mathrm{ng} / \mathrm{mL}, 225.92 \pm$ $98.30 \mathrm{ng} / \mathrm{mL}$ and $250.26 \pm 92.38 \mathrm{ng} / \mathrm{mL}$, respectively. Four patients had increases in peak CP $(57.1 \%)$, and 5 (71.4\%) had an increase in AUC at T6.

There was an inverse correlation between $\mathrm{HbAlc}$ and either peak CP $(\mathrm{r}=-0.821, \mathrm{p}=0.023)$ or CP AUC $(\mathrm{r}=-0.929, \mathrm{p}=0.003)$ at $\mathrm{T} 6$, but not with basal CP $(\mathrm{p}=0.25)$. There was no correlation between insulin dose $/ \mathrm{kg}$ and basal CP, peak CP or CP AUC at T6 $(\mathrm{p}=$ $0.7, \mathrm{p}=0.33$, and $\mathrm{p}=0.64$, respectively).

\section{Comparison of ASC + VIT D (group 1) with a previous study with VIT D (group 2) and controls (group 3)}

Data from patients who received ASCs + VIT D (group 1) were compared with data from a previous study (16) where a group received 2,000 UI VIT D (group 2) and another remained on standard insulin treatment (group 3). Clinical data from all 3 groups are described in Table 2.

There was a similar age and gender distribution among groups (Table 2). Basal and peak CP at T0 and T6 in each group are described in Figures 1 and 2. Group 1 had an increase in basal CP over 6 months $(\mathrm{p}=0.018)$, but basal CP remained stable in groups 2 and 3 $(\mathrm{p}=0.58$ and $\mathrm{p}=0.116$, respectively $)$, as shown in Figure 1. In Table 2, there was a difference in basal CP at T6 $(\mathrm{p}=0.028)$ comparing all three groups. For two-bytwo comparisons, the difference was seen only between groups 1 and 3, as shown in supplementary Figure 1 (Figure S1). An increase in basal CP was observed in all patients in group 1 vs. $3 / 4(75 \%)$ and $2 / 6(33.3 \%)$ patients in groups 2 and 3 , respectively $(\mathrm{p}=0.011)$. The percentage of increase in basal CP was higher in patients who received any intervention (ASCs + VIT D or VIT D) than in others $(+48.41 \pm 77.24$ vs. -33.15

Table 2. Age, insulin dose, Hba1C and basal and peak C peptide in group 1 (ASC + VIT D), group 2 (VIT D) and group 3 (controls)

\begin{tabular}{|c|c|c|c|c|}
\hline & $\begin{array}{c}\text { ASC + VIT D } \\
\text { Group } 1(n=7)\end{array}$ & $\begin{array}{c}\text { VIT D } \\
\text { Group } 2(n=4)\end{array}$ & $\begin{array}{c}\text { Controls } \\
\text { Group } 3(n=6)\end{array}$ & p value * \\
\hline Age (years) & $27.14 \pm 6.49$ & $20.75 \pm 6.18$ & $19.17 \pm 4.02$ & $p=0.09$ \\
\hline Female/male & $4(57.1 \%) / 3(42.9 \%)$ & $2(50 \%) / 2(50 \%)$ & $3(50 \%) / 3(50 \%)$ & $p=0.79$ \\
\hline Insulin dose/kg T0 & $0.31 \pm 0.26 \mathrm{Ul} / \mathrm{kg}$ & $0.46 \pm 0.25 \mathrm{Ul} / \mathrm{kg}$ & $0.57 \pm 0.31 \mathrm{Ul} / \mathrm{kg}$ & $p=0.9$ \\
\hline Insulin dose/kg T6 & $0.28 \pm 1.44 \mathrm{Ul} / \mathrm{kg}$ & $0.55 \pm 0.31 \mathrm{Ul} / \mathrm{kg}$ & $0.63 \pm 0.28 \mathrm{UI} / \mathrm{kg}$ & $p=0.89$ \\
\hline Absolute insulin alteration & $-0,028 \pm 0,21 \mathrm{Ul} / \mathrm{kg}$ & $0.08 \pm 0.15 \mathrm{Ul} / \mathrm{kg}$ & $0.06 \pm 0.25 \mathrm{Ul} / \mathrm{kg}$ & $p=0.9$ \\
\hline$\%$ of insulin dose alteration & $15.39 \pm 51.67 \%$ & $20.26 \pm 30.45 \%$ & $23.53 \pm 63.80 \%$ & $p=0.89$ \\
\hline HbA1c T0 & $7.77 \pm 1.14 \%$ & $9.15 \pm 3.05 \%$ & $8.08 \pm 2.4 \%$ & $p=0.89$ \\
\hline $\mathrm{HbA1c}$ T3 & $6.2 \pm 0.49 \%$ & $6.65 \pm 1.03 \%$ & $8,33 \pm 3.25 \%$ & $p=0.38$ \\
\hline HbA1c T6 & $6.55 \pm 0.66 \%$ & $6.37 \pm 0.62 \%$ & $7.87 \pm 2.01 \%$ & $p=0.379$ \\
\hline Basal CP TO (ng/dL) & $0.80 \pm 0.38$ & $0.52 \pm 0.33$ & $0.59 \pm 0.39$ & $p=0.473$ \\
\hline Basal CP T6 (ng/dL) & $1.04 \pm 0.47$ & $0.60 \pm 0.29$ & $0.31 \pm 0.22$ & $p=0.028$ \\
\hline Absolute basal CP modification (ng/dL) & $0.23 \pm 0.14$ & $0.07 \pm 0.57$ & $-0.28 \pm 0.52$ & $p=0.045$ \\
\hline$\%$ basal CP modification & $40.41 \pm 40.79$ & $62.41 \pm 127.08$ & $33.15 \pm 51.6$ & $p=0.107$ \\
\hline Peak CP TO & $2.83 \pm 1,24$ & $1.27 \pm 1.02$ & $1.29 \pm 0.58$ & $p=0.031$ \\
\hline Peak CP T6 & $2.82 \pm 1,24$ & $1.95 \pm 1.38$ & $0.90 \pm 0.48$ & $p=0.011$ \\
\hline Absolute peak CP modification (ng/dL) & $-0.007 \pm 1.08$ & $0.67 \pm 0.36$ & $-0.39 \pm 0.89$ & $p=0.16$ \\
\hline$\%$ peak CP modification & $8.69 \pm 53.1$ & $59.66 \pm 11.38$ & $-17.72 \pm 55.65$ & $p=0.079$ \\
\hline
\end{tabular}

ASC: adipose tissue-derived stem/stromal cells; VIT D: cholecalciferol; Hba1c: glycated hemoglobin; CP: C peptide; T0: before intervention; T6: 6 months after intervention; group 1: ASC + VIT D; group 2: VIT D; group 3: Controls. Basal CP, Peak CP and insulin dose in two by two comparisons are described in supplementary Figures 2 and 3 (Figures S2 and S3). 
$\pm 51.60 \% ; p=0.035)$. No differences were found in percentage of basal CP increase from T0 to T6 between the three groups, as shown in Table $2(\mathrm{p}=0.107)$. Twoby-two comparisons did not show differences between groups in the percentage of $\mathrm{CP}$ alteration from $\mathrm{T} 0$ to T6 after Bonferroni correction ( $\mathrm{p}=0.035, \mathrm{p}=0.257$ and $\mathrm{p}=1.0$ for ASC + VIT D vs controls, VIT D vs controls and ASC + VIT D vs. VIT D, respectively).

Peak CP remained stable after 6 months in all 3 groups as described in Figure 2. In Table 2, there was a difference in peak $\mathrm{CP}$ at $\mathrm{T} 0$ and T6, comparing the three groups $(\mathrm{p}=0.031$ and $\mathrm{p}=0.01 \mathrm{l}$, respectively). In two-by-two comparisons, the difference was significant only between groups $\mathrm{l}$ and 3 at T6 $(\mathrm{p}=0.01)$ (Supplementary Figure 1; Figure S1). The percentage of increase in peak CP did not differ between groups, $\mathrm{p}=0.079$ (Table 2). There was no difference between groups in the frequency of individuals who had an increase in peak CP after 6 months $(\mathrm{p}=0.44)$.

HbAlc improved in group 1 after 6 months $(7.77 \pm$ $1.14 \%$ vs. $6.55 \pm 0.66, p=0.018)$, but had no difference in group $2(\mathrm{p}=0.14)$ and group $3(\mathrm{p}=0.67)$, as shown in Figure 3. Insulin dose $/ \mathrm{kg}$ was similar before and after intervention in all groups (group $1 \mathrm{~T} 0=0.31 \pm 0.26$ $\mathrm{UI} / \mathrm{kg}$ vs. T6 $=0.28 \pm 1.44 \mathrm{UI} / \mathrm{kg}, \mathrm{p}=0.44$; group 2 $\mathrm{T} 0=0.46 \pm 0.25 \mathrm{UI} / \mathrm{kg}$ vs. $\mathrm{T} 6=0.55 \pm 0.3 \mathrm{l} \mathrm{UI} / \mathrm{kg}, \mathrm{p}$ $=0.28$; group $3 \mathrm{~T} 0=0.57 \pm 0.31 \mathrm{UI} / \mathrm{kg}$ vs. $\mathrm{T} 6=0.63$ $\pm 0.28 \mathrm{UI} / \mathrm{kg}, \mathrm{p}=0.46$ ). Two-by-two comparisons between groups are described in supplementary Figure 2 (Figure S2). Percentage of insulin dose increase after 6 months was similar between groups $(\mathrm{p}=0.89)$.

At T6, all patients $(100 \% / \mathrm{n}=7)$ in group 1 were in a honeymoon period (insulin dose $\leq 0.5 \mathrm{UI} / \mathrm{kg}$ with HbAlc $<7.5 \%)$ vs. $75 \%(n=3 / 4)$ in group 2 and $50 \%$ in group $3(\mathrm{n}=3 / 6), \mathrm{p}=0.01$.

At T0, vitamin $\mathrm{D}$ levels did not differ between groups $(33.06 \pm 13.55 \mathrm{ng} / \mathrm{mL}, 27.85 \pm 11.17 \mathrm{ng} / \mathrm{mL}$, $24.1 \pm 8.5 \mathrm{lng} / \mathrm{mL}$ for groups 1,2 and 3 , respectively, $\mathrm{p}=0.26)$. At T6, groups 1 and 2 had similar vitamin $\mathrm{D}$ levels $(45.0 \pm 14.63$ vs. $55.89 \pm 15.78 ; \mathrm{p}=0.41)$, which were higher than in group $3(28.33 \pm 5.44 ; \mathrm{p}=0.002)$. There was no correlation between basal or peak CP and vitamin $\mathrm{D}$ levels in those patients who received oral VIT D $(\mathrm{p}=0.39$ and $\mathrm{p}=0.86$, respectively).
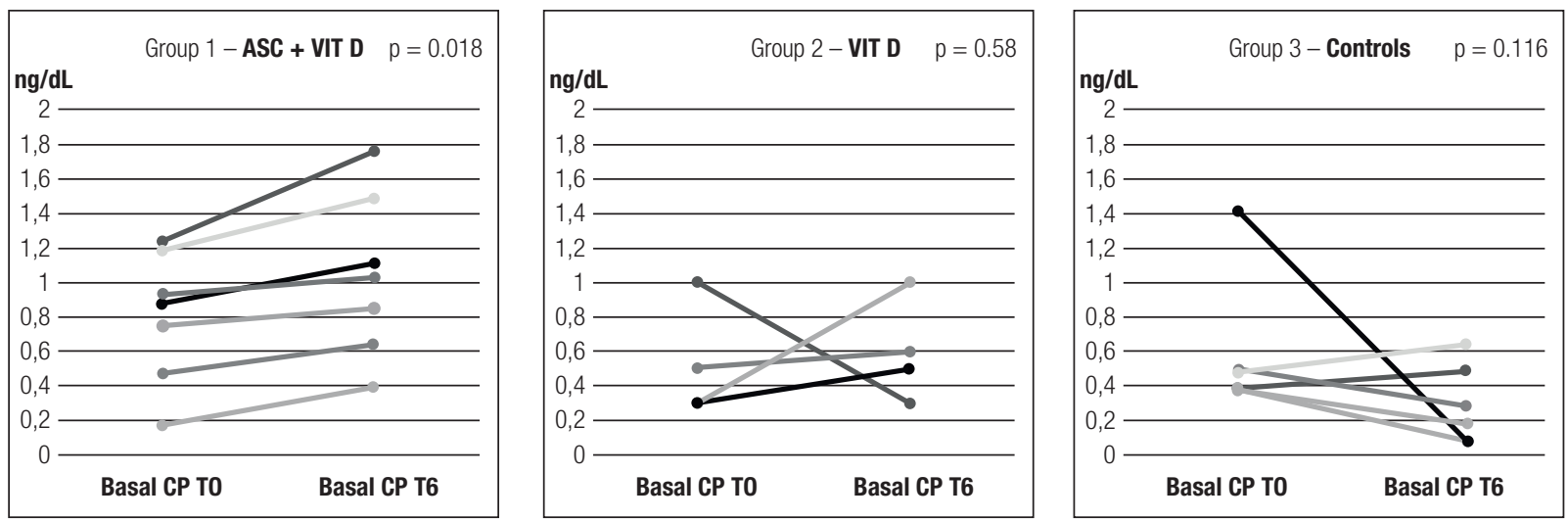

Figure 1. Basal $C$ peptide distribution at T0 and T6 in each group.

Individual patient basal C-peptide before and 6 months after intervention for each group (group 1: ASC + VIT D; group 2: VIT D; group 3: Controls). CP: c peptide; TO: basal; T6: after 6 months; VIT D: vitamin D; ASC: adipose tissue-derived stem/stromal cells.
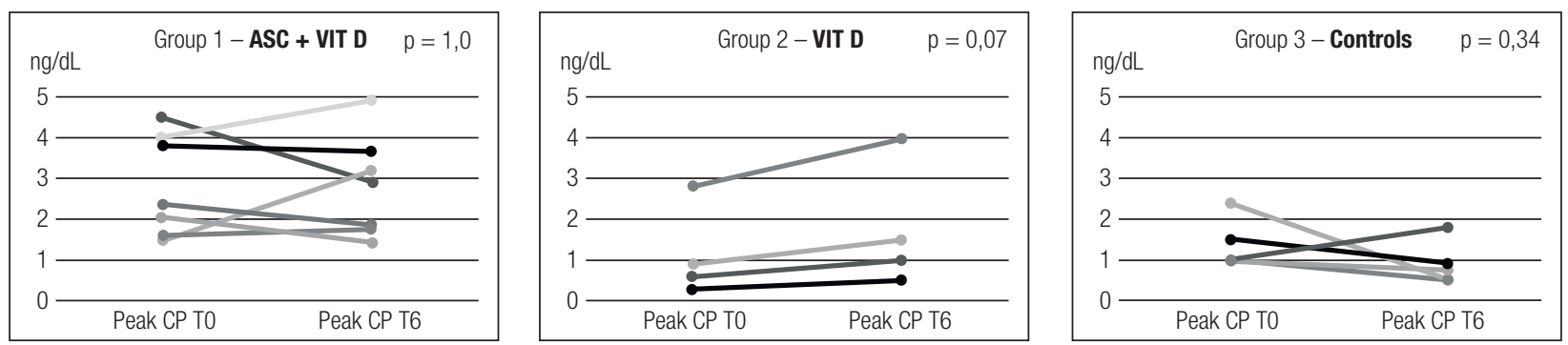

Figure 2. Peak $\mathrm{C}$ peptide distribution at T0 and T6 in each group.

Individual patient peak $C$ peptide before and 6 months after intervention for each group (group 1: ASC + VIT D; group 2:VIT D; group 3: Controls). CP: C peptide; TO: basal; T6: after 6 months; VIT D: vitamin D; ASC: adipose tissue-derived stem/stromal cells. 

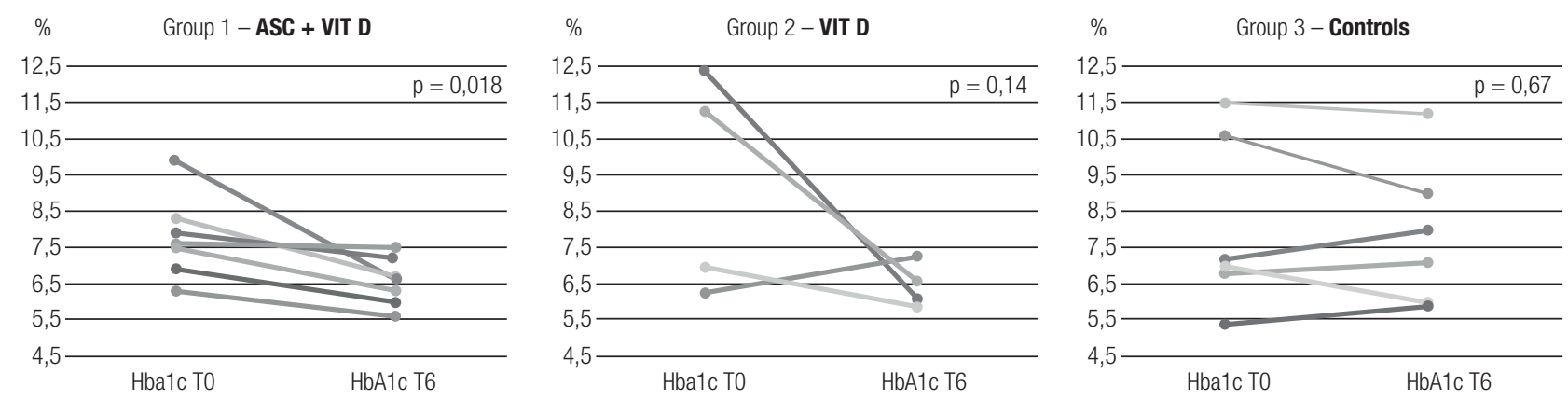

Figure 3. Hba1c at T0 and T6 in each group.

Individual patient basal C-peptide before and 6 months after intervention for each group (group 1: ASC + VIT D; group 2: VIT D; group 3: Controls). CP: C peptide; T0: basal; T6: after 6 months; VIT D: vitamin D; ASC: adipose tissue-derived stem/stromal cells.

\section{DISCUSSION}

This study evaluated the safety and efficacy of allogenic ASCs without immunosuppression associated with 2,000 UI VIT D supplementation for 6 months in patients with recent-onset TID. After intervention, all patients had a good glycemic control and low insulin requirements, without significant decline in $\beta$-cell function, with few or transient complications.

This was the first trial to use allogenic ASCs without immunosuppression in patients with TlD of short duration. Other authors have investigated the role of adult stem cells from different origins in the preservation of $\beta$-cells for patients with TID. HSC transplantation with cyclophosphamide and anti-thymoglobulin led to significant increase in CP and transient insulin independence, but the potential toxicity of immunosuppressive agents limits their widespread clinical use (9). Carlsson and cols. evaluated the efficacy of autologous bone marrow MSC in recent onset TID patients (21). Both AUC and peak CP improved after 1 year when compared to controls with no adverse events. As bone marrow is not easily accessed, subcutaneous adipose tissue might be a more interesting source of MSC (13). Although Thakkar and cols. have tested allogenic and autologous ASC for patients with TID, the study population comprised individuals with long-standing disease, concomitant use of immunosuppressive agents, bone marrow transplantation and ASC culture to generate insulinsecreting cells in vivo and intraportal infusion (22).

Allogenic ASC was used in this trial. Differently from autologous cells, they could potentially replace the autoreactive host immune system with a more tolerant donor profile (23). There is concern whether the immune properties of the MSC are preserved in individuals with diabetes, which favors the use of allogenic cells for transplantation in this scenario. The safety and promising outcome of this clinical trial using allogenic cells encourages the generation of master banks (cryopreserved cells) for cell therapy. ASC can be isolated from young, healthy donors, fully characterized, expanded in vitro and cryopreserved for their use in a range of diseases, including TID.

Therapy with ASC was safe and led to few or transient adverse events. Most patients presented tachycardia during infusion, which resolved soon after its suspension. Transient thrombophlebitis was also frequent. These events might have been associated with high cellularity concentration, high viscosity, or other cell stabilizing products. One patient presented central vein occlusion 3 months after infusion, with complete resolution. This was probably not associated with the therapy since it occurred months after the intervention.

Six months after intervention, there was an absolute increase in basal CP in the group that received ASC + VIT D. As basal endogenous insulin secretion has a micropulsatile pattern and may have paracrine effects in the regulation of glucagon secretion, it is possible that this improvement might influence glycemic control during a fasting state $(24,25)$. Peak $\mathrm{CP}$ and CP AUC remained stable in this period after the intervention with $\mathrm{HbAlc}$ within target and low insulin requirements. Although these findings could represent a honeymoon state, previous data from the Trialnet and others indicate that there is a decrease in CP AUC and peak CP in patients with similar ages in the first 6-12 months of TID $(26,27)$. However, most patients included in Trialnet were Caucasian, and there is scarce information about the progression of the $\beta$-cell function in TID from multiethnic populations. 
In order to determine whether the favorable evolution of $\beta$-cell function was related to the treatment, we compared data from patients who underwent ASC infusion + VIT D with individuals who received standard insulin treatment in this study or in a previous analysis of a similar population, as well as with individuals that received only VIT D as intervention (16). The improvement in basal CP observed in patients that received ASC + VIT D was not seen in the other groups. A difference in basal CP at T6 was observed among the 3 groups, but in two-bytwo comparisons the difference was seen only between group 1 (ASC infusion + VIT D) and 3 (controls). Although this suggests that treatment with ASC + VIT D is associated with better basal CP evolution, this information should still be interpreted cautiously, due to the limited number of patients in each group, the absence of differences in the absolute or percentage of basal CP difference between groups as well as the lack of peak CP alterations or differences in the whole sample, which is a more traditional and reliable marker for $\beta$-cell function.

Patients in group $\mathrm{l}$ had an improvement in $\mathrm{HbAlc}$ without a significant increase in insulin dose $/ \mathrm{kg}$, which might be secondary to the increase in basal insulin secretion observed in those patients. Moreover, all patients in ASC + VIT D therapy group were in honeymoon phase after 6 months, which was superior to that observed in groups that used vitamin $\mathrm{D}$ without ASC $(3 / 4)$ and conventional therapy $(3 / 6)$.

This study indicates a potential benefit of the combination of peripheral ASC infusion + oral VIT D supplementation for patients with the recent onset of TID. The infusion of these cells in the peripancreatic area might have more pronounced effects, as it has been previously shown that part of the stem cells that are infused in peripheral veins migrates to the lungs, which could compromise their immunomodulatory action $(28,29)$. Moreover, it is possible that the slightly beneficial effects of stem cells for patients with the recent onset of TID observed in our group, when compared to more striking results observed in former studies with hematopoietic stem cells (9), might have been due to concomitant immunosuppression used in those. In this study, we administered ASC without immunosuppressive agents to avoid their toxicity (9).

This study has some limitations. First, the limited number of patients might have influenced the results. However, this was a pilot study with the priority of establishing the safety of ASC. As therapy has proven to be safe, further, larger studies may be developed. Second, it is not possible to determine whether the beneficial effect of ASC in pancreatic function was due to immune modulation or secondary to their differentiation in beta cells. Moreover, this was an open study, and most participants accepted entrance only in the intervention arm. Therefore, comparison between individuals that received ASC + VIT D with patients in standard insulin treatment depended mostly on a previous study performed on a similar population. Finally, a longer follow-up is necessary to investigate the long-term safety and efficacy of ASC + VIT D. However, this was the first study to show the safety of allogenic ASC without immunosuppression in patients with TID of short duration, which opens a new possibility for clinical trials.

To conclude, therapy with allogenic ASC + VIT D without immunosuppression was safe and might have a role in the preservation of $\beta$-cells in patients with recent-onset TID.

Authorship: D.B.A., M.F.C.P, C.C.S and D.L.S. researched data. J.R.D. K.R.S.P and L.S.B. wrote the manuscript and researched data. M.R, C.L.K.R., L.Z. reviewed/edited the manuscript and contributed to the discussion. R.R contributed to the supervision of statistical analysis. C.E.B.C., M.G., S.D., J.E.P.O. and A.M. contributed to the discussion and reviewed the manuscript. P.R.S.B, A.C.S and D.R.D processed the ASC cells. D.L.S is the corresponding author. The manuscript has been read and approved by all authors.

Acknowledgements: the National Institute of Metrology, Quality and Technology (Inmetro), Duque de Caxias, are acknowledged for supplying facilities for flow cytometry analysis.

Funding statement: we received financial support from the institutions Coordenação de Aperfeiçoamento de Pessoal de Nivel Superior (Capes) and Fundação de Amparo à Pesquisa do Rio de Janeiro (FAPERJ).

Disclosure: no potential conflict of interest relevant to this article was reported.

\section{REFERENCES}

1. Atkinson MA. The Pathogenesis and Natural History of Type 1 Diabetes. Cold Spring Harb Perspect Med. 2012;2(11).

2. Knip M, Veijola R, Virtanen SM, Hyoty H, Vaarala O, Akerblom HK. Environmental triggers and determinants of type 1 diabetes. Diabetes. 2005;54 Suppl 2:S125-36.

3. Creusot RJ. Initiating type I diabetes: new suspects in the lineup. Nature Med. 2013;19(1):18-20.

4. Achenbach $P$, Bonifacio E, Koczwara K, Ziegler AG. Natural history of type 1 diabetes. Diabetes. 2005;54 Suppl 2:S25-31. 
5. The Diabetes Control and Complications Trial Research Group. Effect of intensive therapy on residual beta-cell function in patients with type 1 diabetes in the diabetes control and complications trial. A randomized, controlled trial. Ann Intern Med. 1998;128(7):517-23.

6. Ludvigsson J. Novel therapies in the management of type I diabetes mellitus. Panminerva Med. 2012;54(4):257-70.

7. Gallagher MP, Goland RS, Greenbaum CJ. Making progress: preserving beta cells in type 1 diabetes. Ann N Y Acad Sci. 2011;1243:119-34.

8. Lernmark A, Larsson HE. Immune therapy in type 1 diabetes mellitus. Nature Rev Endocrinol. 2013;9(2):92-103.

9. Couri $C E$, Oliveira MC, Stracieri AB, Moraes DA, Pieroni F, Barros GM, et al. C-peptide levels and insulin independence following autologous nonmyeloablative hematopoietic stem cell transplantation in newly diagnosed type 1 diabetes mellitus. JAMA. 2009;301(15):1573-9.

10. Chhabra P, Brayman KL. Stem cell therapy to cure type 1 diabetes: from hype to hope. Stem Cells Transl Med. 2013;2(5):328-36.

11. Abdi R, Fiorina $P$, Adra $C N$, Atkinson $M$, Sayegh $M H$. Immunomodulation by mesenchymal stem cells: a potential therapeutic strategy for type 1 diabetes. Diabetes. 2008;57(7):1759-67.

12. Weiss ARR, Dahlke MH. Immunomodulation by Mesenchymal Stem Cells (MSCs): Mechanisms of Action of Living, Apoptotic, and Dead MSCs. Front Immunol. 2019;10:1191.

13. Baptista LS, do Amaral RJ, Carias RB, Aniceto M, Claudio-daSilva C, Borojevic R. An alternative method for the isolation of mesenchymal stromal cells derived from lipoaspirate samples. Cytotherapy. 2009;11(6):706-15.

14. Gregori S, Giarratana N, Smiroldo S, Uskokovic M, Adorini L. A 1alpha,25-dihydroxyvitamin $\mathrm{D}(3)$ analog enhances regulatory T-cells and arrests autoimmune diabetes in NOD mice. Diabetes. 2002;51(5):1367-74.

15. Gysemans CA, Cardozo AK, Callewaert $H$, Giulietti A, Hulshagen $\mathrm{L}$, Bouillon $\mathrm{R}$, et al. 1,25-Dihydroxyvitamin D3 modulates expression of chemokines and cytokines in pancreatic islets: implications for prevention of diabetes in nonobese diabetic mice. Endocrinology. 2005;146(4):1956-64.

16. Gabbay MA, Sato MN, Finazzo C, Duarte AJ, Dib SA. Effect of cholecalciferol as adjunctive therapy with insulin on protective immunologic profile and decline of residual beta-cell function in new-onset type 1 diabetes mellitus. Arch Pediatr Adolesc Med. 2012;166(7):601-7.

17. Gregoriou E, Mamais I,Tzanetakou I, Lavranos G, Chrysostomou S. The Effects of Vitamin D Supplementation in Newly Diagnosed Type 1 Diabetes Patients: Systematic Review of Randomized Controlled Trials. Rev Diabet Stud. 2017;14(2-3):260-8.
18. Hyppönen $E$, Läärä $E$, Reunanen $A$, Järvelin MR, Virtanen SM. Intake of vitamin $D$ and risk of type 1 diabetes: a birth-cohort study. Lancet. 2001;358(9292):1500-3.

19. Grammatiki M, Rapti E, Karras S, Ajjan RA, Kotsa K. Vitamin D and diabetes mellitus: Causal or casual association? Rev Endocr Metab Disord. 2017;18(2):227-41.

20. Evert $A B$, Boucher JL, Cypress M, Dunbar SA, Franz MJ, Mayer-Davis EJ, et al. Nutrition Therapy Recommendations for the Management of Adults with Diabetes. Diabetes Care. 2014;37(Suppl 1):S120-43.

21. Carlsson PO, Schwarcz E, Korsgren O, Le Blanc K. Preserved betacell function in type 1 diabetes by mesenchymal stromal cells. Diabetes. 2015;64(2):587-92.

22. Thakkar UG, Trivedi HL, Vanikar AV, Dave SD. Insulin-secreting adipose-derived mesenchymal stromal cells with bone marrowderived hematopoietic stem cells from autologous and allogenic sources for type 1 diabetes mellitus. Cytotherapy. 2015;17(7):940-7.

23. Hugle T, Daikeler T. Stem cell transplantation for autoimmune diseases. Haematologica. 2010;95(2):185-8.

24. Hosokawa Y, Kozawa J, Nishizawa H, Kawamori D, Maeda N, Otsuki $\mathrm{M}$, et al. Positive correlation between fasting plasma glucagon and serum C-peptide in Japanese patients with diabetes. Heliyon. 2019;5(5):e01715.

25. Meier JJ, Pennartz C, Schenker N, Menge BA, Schmidt WE, Heise $\mathrm{T}$, et al. Hyperglycaemia is associated with impaired pulsatile insulin secretion: effect of basal insulin therapy. Diabetes Obes Metab. 2013;15(3):258-63.

26. Greenbaum CJ, Beam CA, Boulware D, Gitelman SE, Gottlieb $\mathrm{PA}$, Herold $\mathrm{KC}$, et al. Fall in C-peptide during first 2 years from diagnosis: evidence of at least two distinct phases from composite Type 1 Diabetes TrialNet data. Diabetes. 2012;61(8):2066-73.

27. Shields BM, McDonald TJ, Oram R, Hill A, Hudson M, Leete P, et al. C-Peptide Decline in Type 1 Diabetes Has Two Phases: An Initial Exponential Fall and a Subsequent Stable Phase. Diabetes Care. 2018;41(7):1486-92.

28. Chavakis $E$, Urbich $C$, Dimmeler S. Homing and engraftment of progenitor cells: a prerequisite for cell therapy. J Mol Cell Cardiol. 2008;45(4):514-22.

29. Tang K, Xiao X, Liu D, Shen Y, Chen Y, Wang Y, et al. Autografting of bone marrow mesenchymal stem cells alleviates streptozotocininduced diabetes in miniature pigs: real-time tracing with MRI in vivo. Int J Mol Med. 2014;33(6):1469-76. 


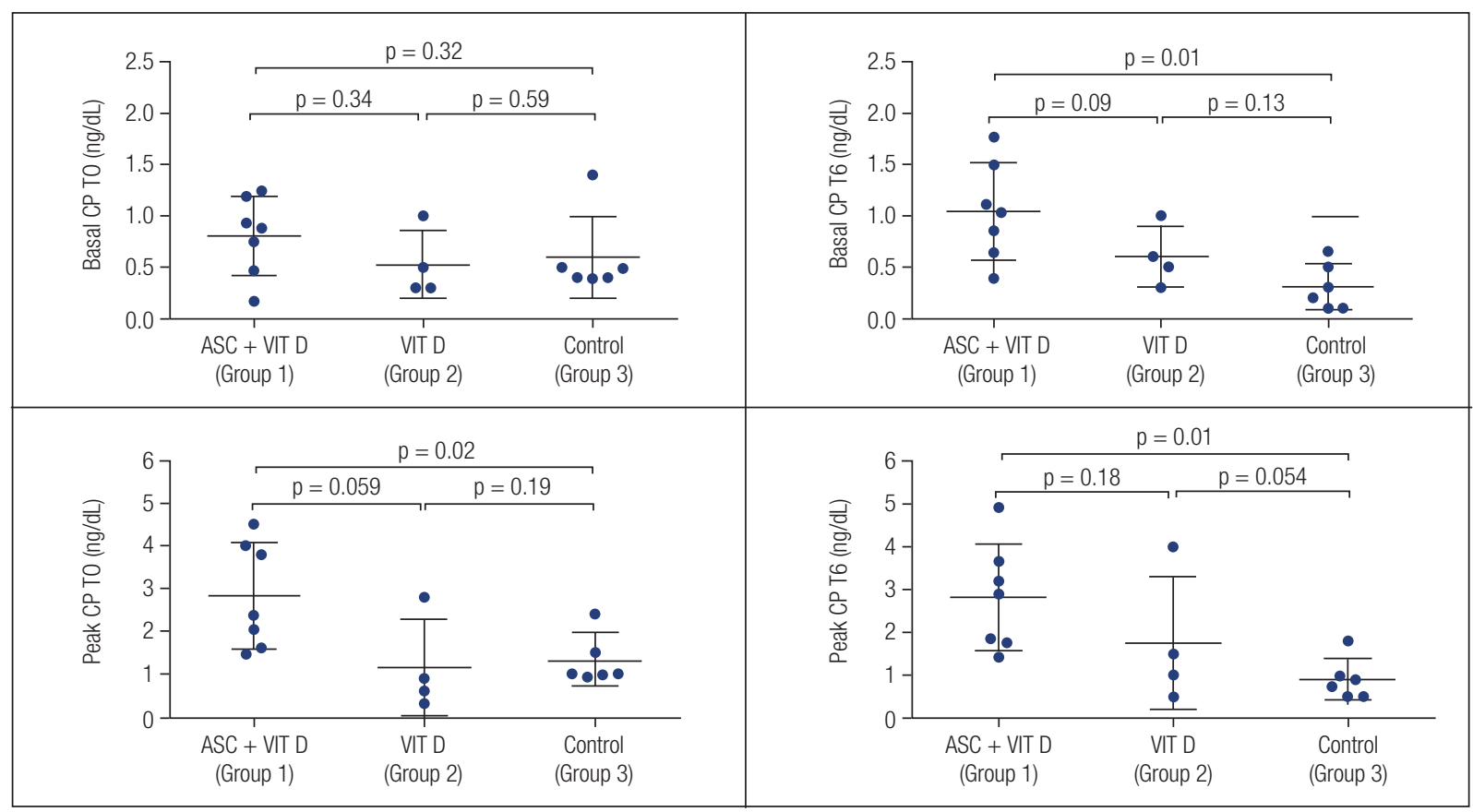

Supplementary figure 1 (figure S1). Basal and peak CP before (T0) and 6 months (T6) after ASC infusion and VIT D supplementation. *P value with Bonferroni correction, level of significance of 0.017 .

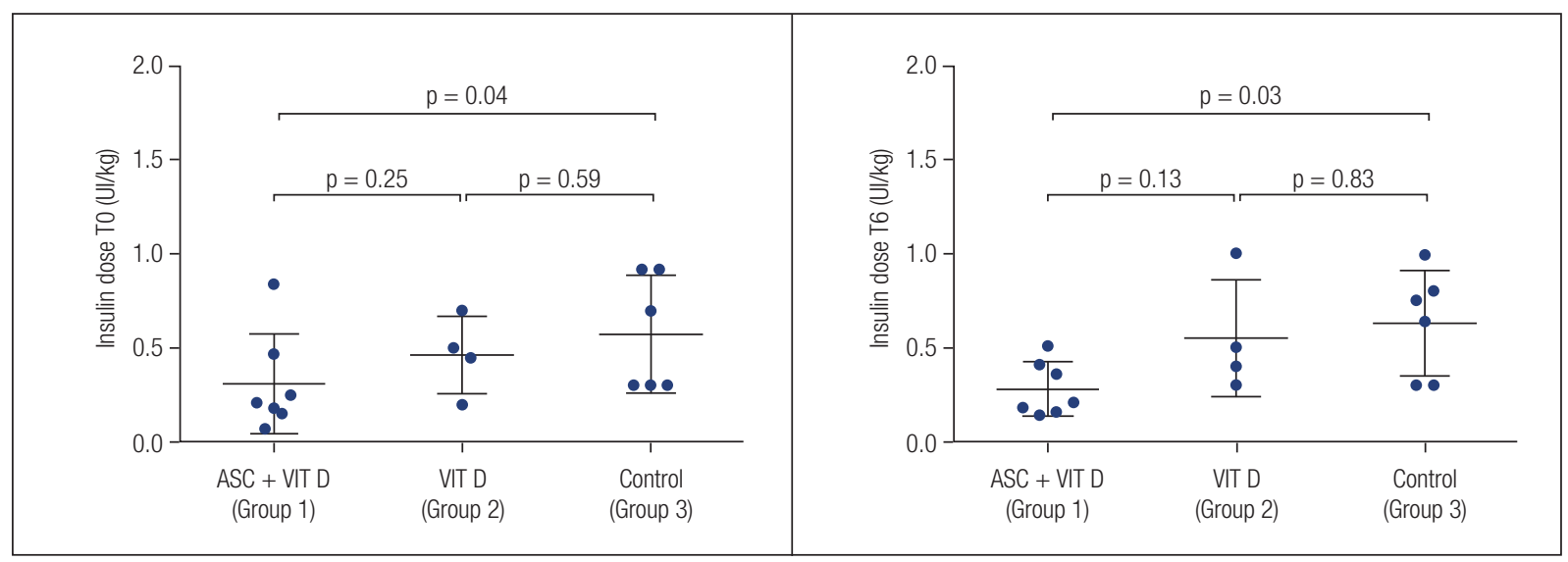

Supplementary figure 2 (figure S2) 2. Insulin dose/kg before (T0) and 6 months after ASC infusion and VIT D supplementation.

Figure 2 describes insulin dose/kg before (T0) and 6 months (T6) after intervention for each group (group 1: ASC + VIT D; group 2: VIT D; group 3: Controls); T0: basal; T6: after 6 months; VIT D: vitamin D; ASC: adipose tissue-derived stem/stromal cells. P values represent comparisons two-by-two.

${ }^{*} \mathrm{P}$ value with Bonferroni correction, level of significance of 0.017 .

Supplementary table 1. Flow cytometer

\begin{tabular}{|c|c|c|c|c|c|c|c|c|c|c|c|c|c|c|}
\hline Marker & CD 105 & CD 73 & CD 90 & CD 29 & CD 166 & CD 44 & CD 36 & CD 14 & CD 34 & CD 45 & CD 19 & HLA-DR & CD 31 & CD 106 \\
\hline $\mathrm{M}$ & $2 \%$ & $51,16 \%$ & $66 \%$ & 4 & 09\% & 8 & b & $0,71 \%$ & $0,67 \%$ & 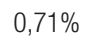 & $50 \%$ & 5 & $39 \%$ & $7 \%$ \\
\hline DP & 055 & 415 & 434 & 442 &, 467 & 395 & 0,131 & 0,038 & , ,005 & 0,007 & , ,003 &, 005 & 0,002 & 0,039 \\
\hline
\end{tabular}

Data are means \pm SD $(95 \% \mathrm{Cl})$.

FITC-labeled CD14 (BD\#555397), CD45 (BD\#555482), CD19 (BD\#555412), CD44 (BD\#555478); PE-labeled CD73 (BD\#550257), CD90 (BD\#555596), CD166 (BD\#559263), PerCP-labeled HLA-DR (BD\#551375); APC-labeled CD34 (BD\#555824), CD105 (BD\#562408), CD29 (BD\#559883) all purchased from BD (Pharmingen). At least 100.000 events were acquired on a BD FACSCalibur ${ }^{\mathrm{TM}}$ flow cytometer (BD Biosciences), and data were analyzed using FlowJo 10 (TreeStar) software11A. 